\title{
GeoGebra as a Means for Understanding Limit Concepts
}

\author{
Puspita Sari \\ Jakarta State University, Indonesia \\ puspitaunj@gmail.com
}

\begin{abstract}
Limit is a major concept in calculus that underpins the concepts of derivatives and integrals. The common misconception about limits is that students treat the value of a limit of a function as the value of a function at a point. This happens because usually the teaching of limit only leads to a procedural understanding (Skemp, 1976) without a proper conceptual understanding. Some researchers suggest the importance of geometrical representations to a meaningful conceptual understanding of calculus concepts. In this research, GeoGebra as a dynamic software is used to support students' understanding of limit concepts by bridging students' algebraic and geometrical thinking. In addition to this, realistic mathematics education (RME) is used as a domain theory to develop an instructional design regarding how GeoGebra could be used to illustrate and explore the limit concept of so that students will have a meaningful understanding both algebraically and geometrically. Therefore, this research aims to explore the hypothetical learning trajectory in order to develop students' understanding of limit concepts by means of GeoGebra and an approach based on RME. The results show that students are able to solve limit problems and at the same time they try to make sense of the problem by providing geometrical representations of it. Thus, the use of geometric representations by GeoGebra and RME approach could provide a more complete understanding of the concepts of limit. While the results are interesting and encouraging and provide some promising directions, they are not a proof and a much larger study would be needed to determine if the results are due to this approach or due to the teachers' enthusiasm, the novelty effect or what is known as the Hawthorne Effect.
\end{abstract}

Keywords: calculus, design research, GeoGebra, limit, RME

\section{Introduction}

Calculus has been one of the most fundamental concepts of various areas in life, such as physics, science, engineering, finance, etc. Moreover, calculus is a compulsory subject not only for college students but also high school students. Most of the teaching and learning of calculus in the classroom is still oriented towards the technical procedures in solving problems without having a sufficient understanding of the underlying concepts. Ahuja et al. (1998), Gravemeijer and Doorman (1999), Lee (2006), and Weigand (2014) stress the importance of geometrical representations in teaching and learning of calculus to assist students to have a meaningful conceptual understanding.

Limit concepts play a central role in understanding the concepts of derivative and integral in calculus. Based on Weigand (2014), a conceptual understanding of the formal limit concepts is challenging for students and requires explanations and visualizations using different representations (beyond the symbolic representation). Furthermore, the understanding of construction or calculation process of limit in the sense of step-by-step processes on numerical and graphical levels is essential. The understanding of limit concepts beyond a formal definition of limits can be supported by computer visualizations. 
Over the last few decades, the use of innovative technology in calculus teaching and learning has been an interest in mathematics education (Gravemeijer \& Doorman, 1999; Hohenwarter et al., 2008; Özmantar, 2009; Diković, 2009; Haciomeroglu \& Andreasen, 2013). By means of technology, the teaching and learning of calculus has shifted into more active and dynamic ways where students can explore various mathematical concepts with multi representations.

In this research, a dynamic mathematics software GeoGebra was used in the teaching and learning of limit concepts. GeoGebra is an open-source software for mathematics teaching and learning that offers geometry, algebra, and calculus features in a fully connected and easyto-use software environment. By using GeoGebra, students are able to explore and rediscover mathematical concepts in different ways using dynamic mathematics software (Hohenwarter, et al., 2008). Therefore, it is believed that GeoGebra could support the development of students' thinking in understanding limit concepts by providing its visualization or geometrical representations of the formal definition of limit.

The need of a contextual situation in developing an instructional design for the teaching and learning of limit concepts is as important as providing the means. In other words, a specific domain theory of realistic mathematics education (RME) was used in this research in designing the instructional process or the so-called the hypothetical learning trajectory (HLT). RME was first developed in 1971 in response to a need to improve the quality of mathematics teaching and learning in the Netherlands. The main features of RME are the use of contexts and models, students' own constructions and productions, interactivity, and intertwinement (Treffers, 1987).

Although considerable studies have been done in the teaching and learning of calculus, it is noteworthy that the research in calculus learning and teaching has not capitalized on advances in design research to further link theories of learning with theories of instructional design (Rasmussen et al., 2014). Moreover, it is claimed that a design research provides a productive perspective for theory development. Its results which encompass design of activities, materials, and systems are the most useful results regarding the improvement of the education system as the ultimate goal of educational research (Edelson, 2002). Therefore, by using design research methodology, this paper aims to explore the HLT to develop students' understanding of limit concepts by means of a dynamic software GeoGebra and an approach based on RME theory.

\section{Methodology}

The methodology used in this research is design research which was first proposed as developmental research by Freudenthal in the Netherlands to develop the so-called domainspecific instruction theory of RME (Gravemeijer \& Cobb, 2006; Freudenthal, 1991). The 
purpose of this design research was to develop a class of theories about both the process of learning and the means designed to support that learning, the learning of individual students, of a classroom community, of a professional teaching community, or of a school or school district viewed as an organization (Cobb et al., 2003).

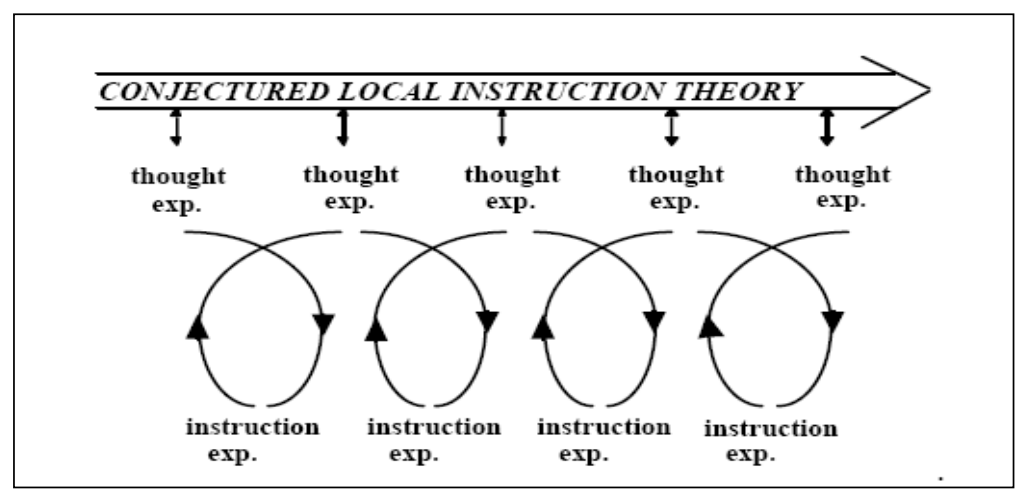

Figure 1. Reflexive relation between theory and experiments (Gravemeijer \& Cobb, 2006)

Basically, a design research has three essential phases: (1) the design and preparation phase (thought experiment), (2) the teaching experiment phase (instruction experiment), and (3) the retrospective analysis phase (Gravemeijer \& Cobb, 2006; Cobb et al., 2003). Each of these forms a cyclic process both on its own and in a whole design research. Therefore, the design experiment consists of cyclic processes of thought experiments and instruction experiments (Freudenthal, 1991).

In the first phase of this design research, the instructional design namely the HLT was developed under the guidance of the domain-specific instruction of theory RME, and then put to the test in the teaching experiment phase, and finally the conjectures were either proved or disproved in the analysis phase. In this respect, the conjectured local instruction theory guided the cyclically teaching experiment phase while the experiment contributed to the development of the local instruction theory.

The teaching experiment was conducted in Jakarta State University during the course of Differential Calculus academic year 2015/2016 with a class consisted of 49 students. The data collected during the teaching experiment consisted of video recording of the classroom activities, interviews, students' written test, and field notes in every meeting. The field notes consisted of the development of students' thinking in understanding limit concepts as well as students' contribution and interactivity in relation to the GeoGebra as a means to support the learning and the RME approach. During the teaching experiment, the researcher also acted as an observer along with another observer.

The retrospective analysis dealt with a set of data collected during the teaching experiment where the HLT was compared with students' actual learning. The HLT functioned 
as guidelines determining what the researcher should focus on in the analysis. The results of the retrospective analysis formed the basis for adjusting the HLT and for answering the research questions.

To ensure the quality of data and instruments as well as to justify the results (the HLT including its instructional activities) of the design research, the research refer to the methodological norm of reliability (virtual replicability) and validity. A criterion for virtual replicability is 'trackability' (Gravemeijer \& Cobb, 2001 as cited in Bakker, 2004). This means that the readers must be able to track the learning process of the researcher and to reconstruct their study; failures and successes, procedures followed, conceptual framework used, and reasons for making certain choices must all be reported. Furthermore, internal reliability can be interpreted as inter-subjective agreement among the researchers on the project. Meanwhile, the design research should provide a basis for adaptation to other situations by offering a thick description (results) of what happened in the classroom (Gravemeijer \& Cobb, 2006). That is what is meant by the ecological validity of this design research.

\section{Results and Discussion}

Results of this research were described qualitatively where the data were collected from the video recording of the classroom situation, field notes of students' activities and discussion, and students' written test. The development of a number of students' thinking was analyzed, not only as individuals but also their participation in and contribution to the development of classroom mathematical practice. The role of GeoGebra was highlighted as well in supporting the development of students' understanding of limit concepts. On top of that, the HLT was compared to the actual learning process that happened in the teaching experiment. The following section describes the HLT along with the results obtained from the teaching experiment.

Before the teaching experiment was conducted, a number of questions had been given to the students in order to identify their previous knowledge and understanding about limit concepts. Most of the students' conceptions about limit were that the value of a limit of $f(x)$ when $x$ approaches $c$ is the same as the value of $f(c)$, that is if $\lim _{x \rightarrow c} f(x)=L$ then $f(c)=L$. Students often explained the procedural techniques in solving limit problems, either by substitution or factorization of the function. However, they failed to explain "What happens to the function $f(x)$ as $x$ gets close to constant $c$ but different from $c$ ?"

Based on the above evidence, students tended to think of limit as limit problems that they have to solve algebraically. In other words, students did not have the concept image of limit or the visualization of a function when $x$ approaches some constant. Diagram in Figure 2 shows that the concepts of graphs and functions underlie the limit concept, where limit is 
essential to the development of derivatives and integrals concepts in calculus. Therefore, the graphic function was chosen as the context to start the learning trajectory in order to acquire the intuitive meaning of limit.

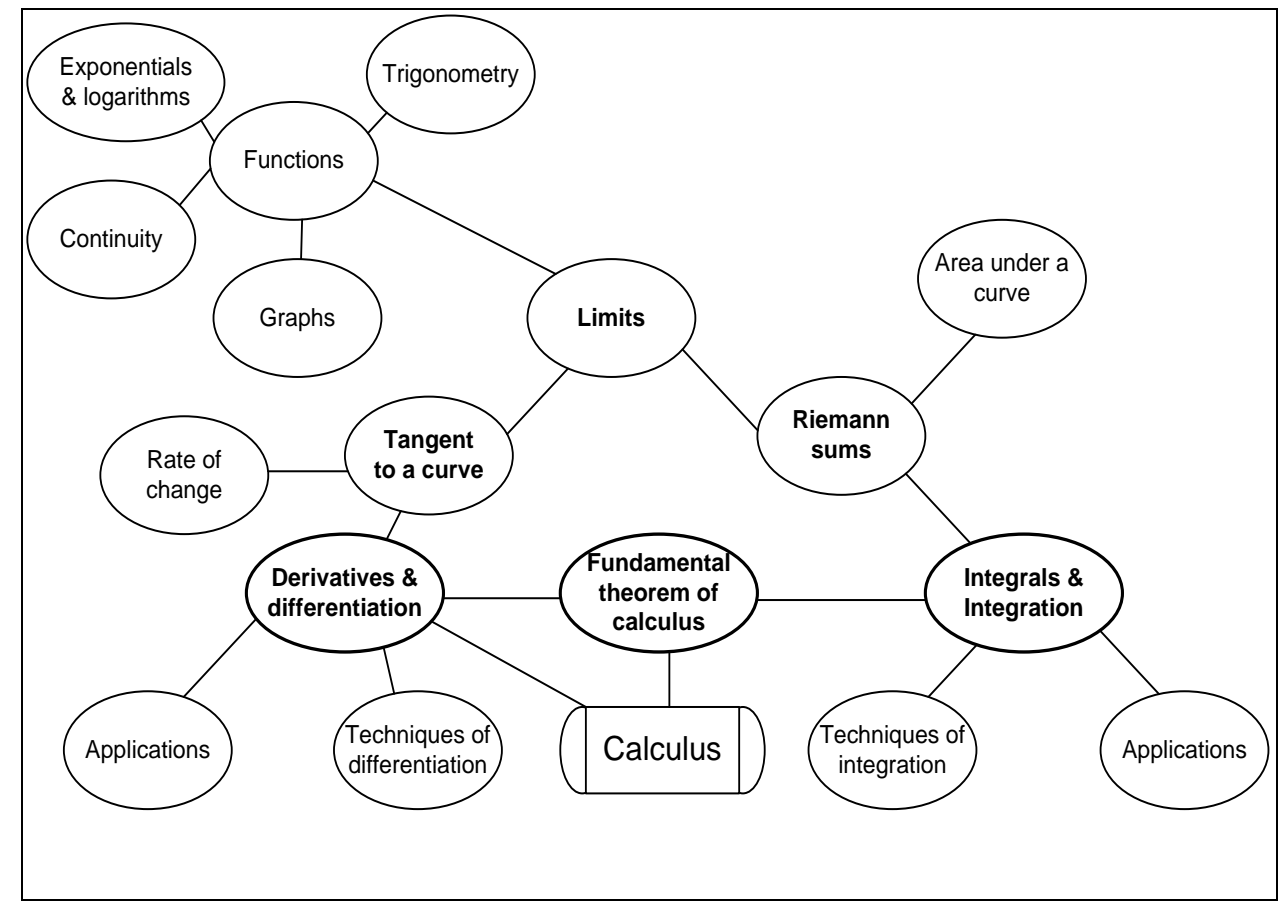

Figure 2. Concepts that underlie the calculus (Lee, 2006)

Moreover, a graph of a discontinuous function was chosen to manage students' misconceptions about limit. Accordingly, students were expected to be able to think geometrically and algebraically in developing the intuitive meaning of limit.

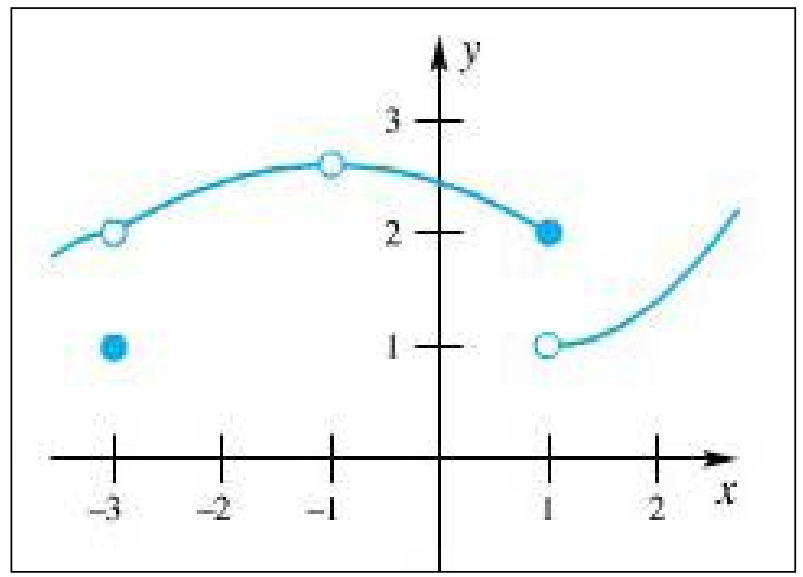

Figure 3. A graph of discontinuous function

By showing the above graph to students and asking "What happens to $f(x)$ as $x$ approaches 1?", students were able to reconstruct their understanding about limit, and at the same time, they constructed the concepts of right-hand and left-hand limits. Moreover, the 
graph in Figure 4 was able to strengthen students' intuitive notions of limit by investigating the behavior of the function at certain points.

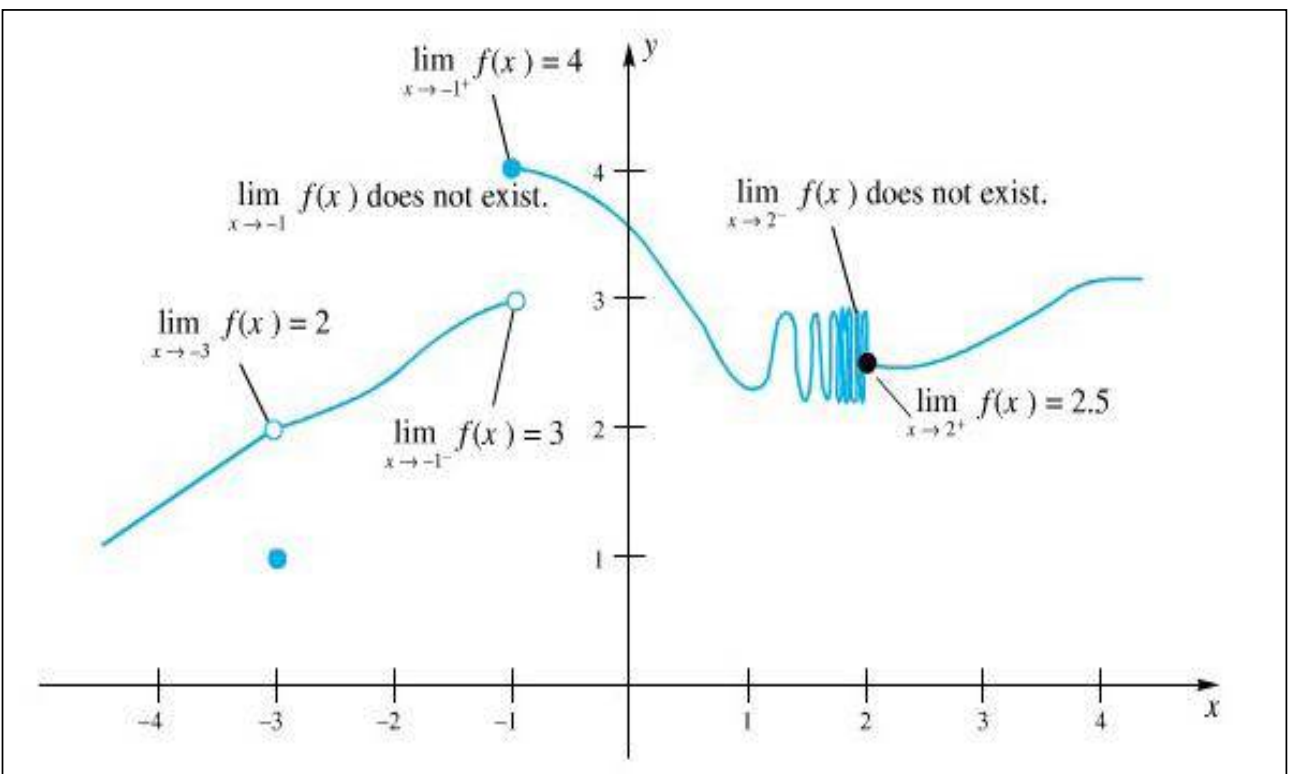

Figure 4. A graph of discontinuous function (Varberg et al., 2007, p.59)

On the next level, the software GeoGebra was applied to construct the formal definition of a limit. By providing the dynamic geometrical representation in GeoGebra, students were able to construct the idea of an arbitrary small positive integer epsilon $(\varepsilon)$ in the neighborhood of $L$ and the corresponding small positive integer delta $(\delta)$ in the neighborhood of $c$.

\section{Definition Precise Meaning of Limit}

To say that $\lim _{x \rightarrow c} f(x)=L$ means that for each given $\varepsilon>0$ (no matter how small) there is a corresponding $\delta>0$ such that $|f(x)-L|<\varepsilon$, provided that $0<|x-c|<\delta$; that is,

$$
0<|x-c|<\delta \Rightarrow|f(x)-L|<\varepsilon
$$

Source: Varberg, Purcell, \& Rigdon (2007, p. 62)

The advantage of using GeoGebra is its dynamic feature enable us to see how the changes of the chosen epsilon affect the changes of delta. By using GeoGebra, students can investigate the relation between epsilon and delta geometrically along with the algebraic analysis when giving a formal proof to a limit problem (see Figure 5).

There was a huge progress in terms of culture in the classroom. During the teaching experiments, students got used to working in groups. They had responsibilities to share ideas and contribute to each other. Students were very active in discussing the solution to the problems, for instance, when a student wrote down a solution of the given problem on the 
whiteboard and there was a little error, then other students corrected, and together they contributed in improving the solution of the problem being discussed.

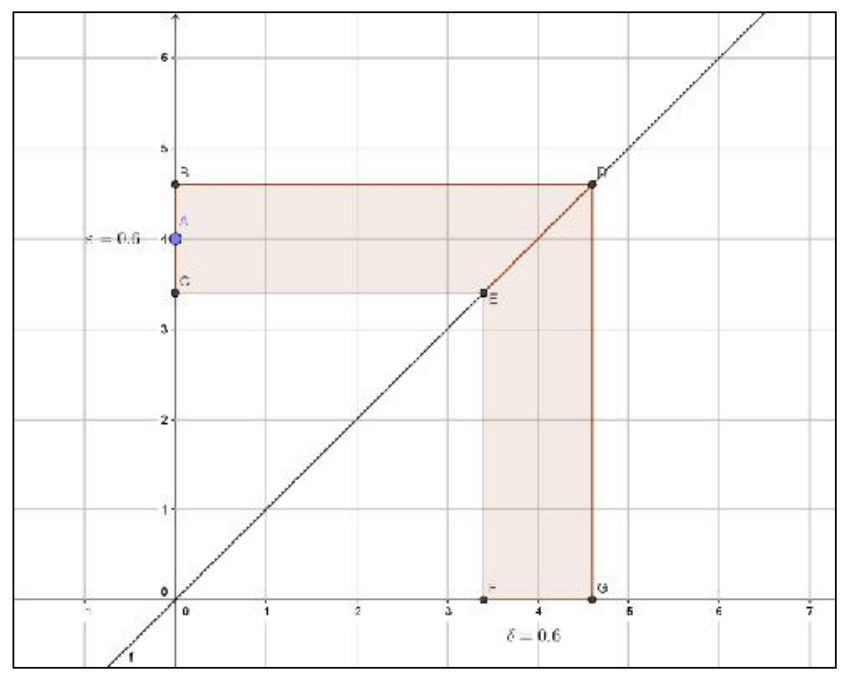

Figure 5. A screenshot of dynamic visualization of the formal definition of limit

Based on the results of the concept review, most of the students could manage their misconceptions about limit. Figure 6 shows the questions given to students to review their conceptual understanding of limit. The results show that 20 out of 38 students could respond correctly problems number 1 and 4, while less than a half of them could answer correctly problems number 2, 3, and 5. A total of 18 students answered correctly problems number 2, 17 students for problem number 5 , and 13 students for problem number 2.

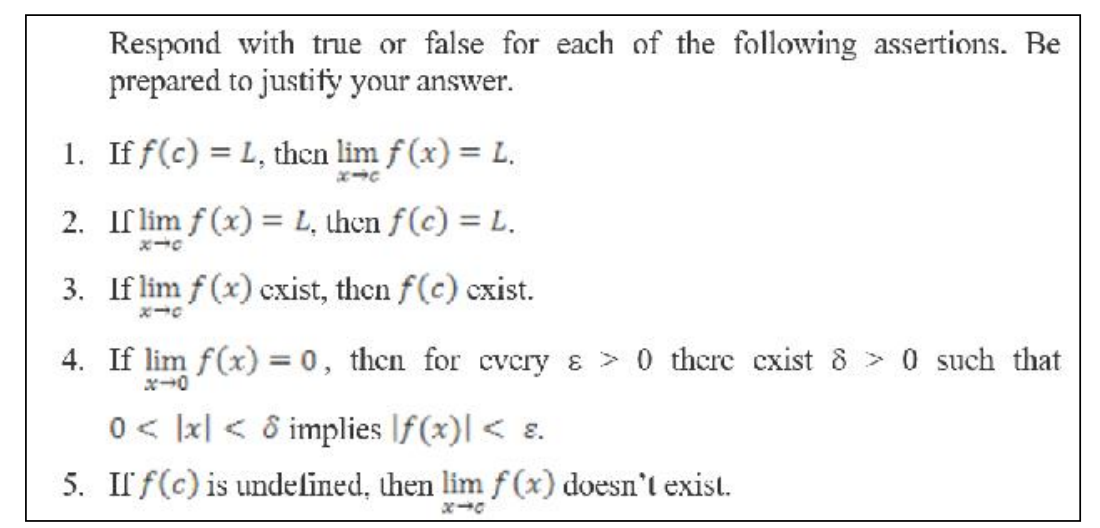

Figure 6. Questions for concepts review

In addition, from 38 students enrolled in the mid test there were 14 students who were able to give a complete formal proof of the limit, 7 students made a little error, and 15 students were successful in the preliminary analysis but did not give the formal proof, while the other 2 students did not respond correctly to the problem instruction. 
Figure 7 is an example of a common student's mistake in proving $\lim _{x \rightarrow 1} \frac{2+4 x}{3}=2$ by using formal definition. Student \#2 was able to give the preliminary analysis of the formal proof and succeeded in obtaining the value of delta, i.e. $\delta=3 \varepsilon / 4$, but she omitted the constant factor $4 / 3$ when substituting $\delta=3 \varepsilon / 4$ for ${ }^{4} / 3^{|x-1|}$ in order to obtain $\varepsilon$ instead of $3 \varepsilon / 4$. Although some mistakes occurred, the result of the concept review and students' formal proof using the definition of limit suggests that most of the students managed their misconceptions intuitively and showed their understanding of limit formally.

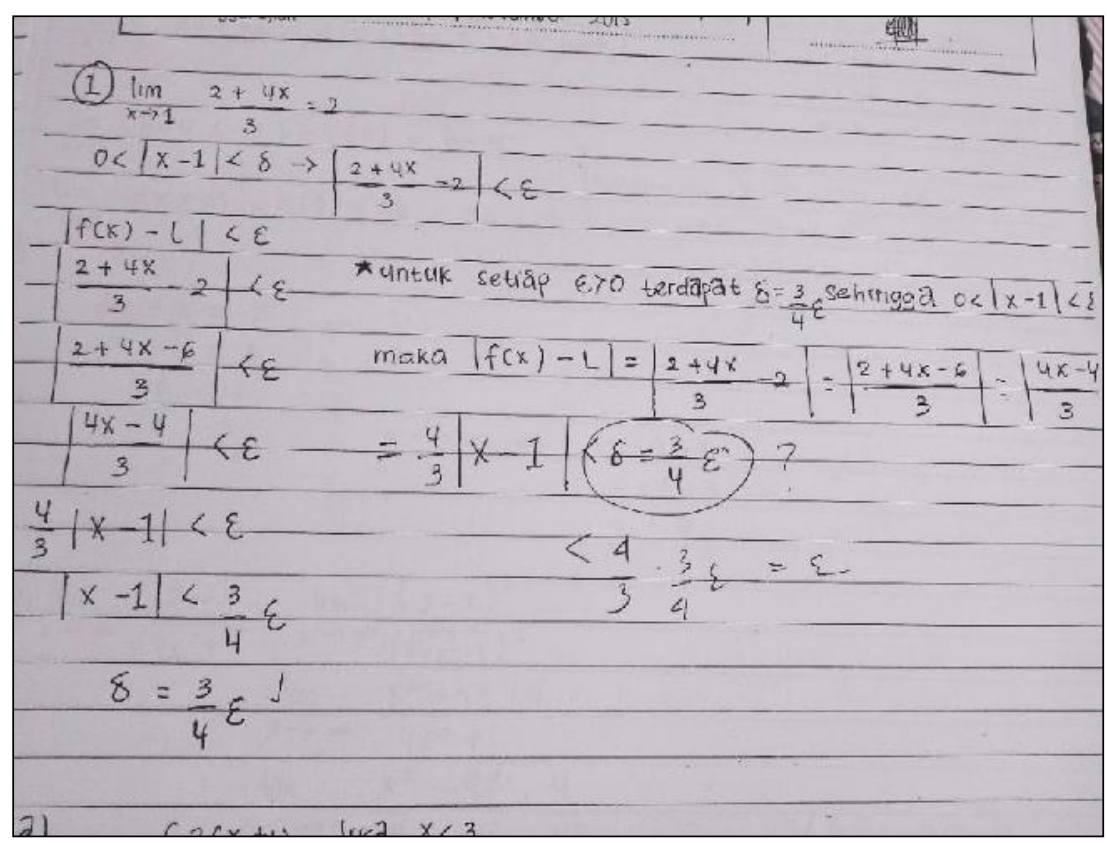

Figure 7. Common mistake in the formal proof of limit (Student \#1)

Furthermore, the students' understanding of limit can also be seen in Figure 8 which depicts another student's thinking in solving the following problem:

$$
\text { Find } \lim _{x \rightarrow 3} f(x) \text { if } \mathrm{f}(\mathrm{x})= \begin{cases}2(\mathrm{x}+1) & \text { jika } \mathrm{x}<3 \\ 4 & \text { jika } \mathrm{x}=3 \\ \mathrm{x}^{2}-1 & \text { jika } \mathrm{x}>3\end{cases}
$$

The question was chosen in order to gain information on how students might find the limit when the value of $f(x)$ is different from the limit of $f(x)$ as $x$ approaches 3 . 


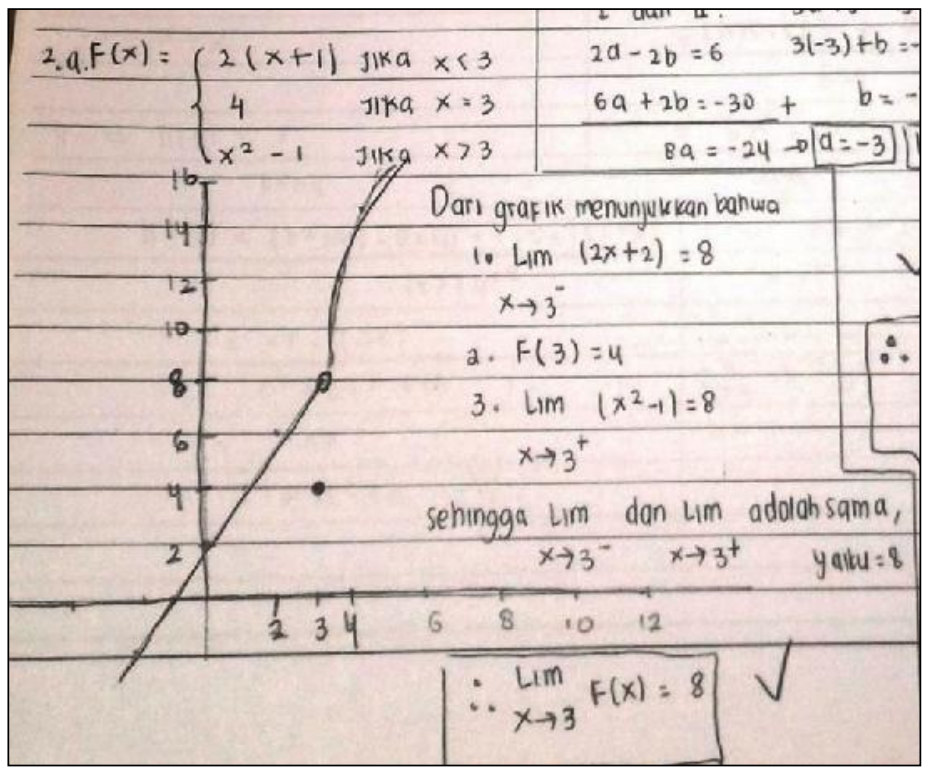

Figure 8. Solution of a limit problem (student \#2)

Among all solutions, the solution in Figure 8 is the most interesting one. Student \#2 solved the problem by graphing the function $f(x)$ first, then she wrote the solution by evaluating the right-hand and left-hand limits and also the function value when $x=3$. Although this problem can be solved without drawing the graph, this student showed an attempt in making sense of the problem by providing the graph of the function. The statement in the solution "Dari grafik menunjukkan bahwa" or "the graph shows that" shows us that she used both geometric and algebraic reasoning in the solution. It was also an evidence that by choosing a meaningful context, that is the graph of functions, and by providing GeoGebra as the means to visualize the concept, the students may have a meaningful conceptual understanding of the concept.

\section{Conclusion}

The evidence shows that GeoGebra supported the development of students' thinking in understanding limit concepts by its dynamic features, where the chosen $\varepsilon$ (epsilon) in the neighborhood of $L$ determines the value of $\delta$ (delta) in the neighborhood of $c$ in the formal definition of limit. Furthermore, the use of context as one of the characteristics of RME helped students to make sense of what they are doing. For instance, drawing the graph of a function as an attempt to make sense of the problem in determining the limit of the function at a certain point and showing in the graph that the right-hand and left-hand limits were equal.

In addition to this, students' contribution and interactivity within the classroom showed a significant influence in the development of students' thinking. By sharing ideas and strategies, giving arguments and justifications, both in whole class and group discussion, students are able to move to a higher level of thinking in understanding limit concepts. 


\section{References}

Ahuja, O.P., Lim-Teo, Suat-Khoh, \& Lee, P. Y. (1998). Mathematics teachers' perspective of their students' learning in traditional calculus and its teaching strategies. Journal of the Korea Society of Mathematical Education Series D: Research in Mathematical Education, 2(2), 89-10.

Bakker, Arthur. (2004). Design research in statistic education on symbolizing and computer tools. Utrecht: Cd- $\beta$ Press.

Cobb, P., Confrey, J., diSessa, A., \& Lehrer, R. (2003). Design experiments in educational research. Educational Researcher, 32(1), 9-13.

Diković, L. (2009), Applications GeoGebra into teaching some topics of mathematics at the college level. ComSIS, 6(2), 191-203.

Edelson, D. C. (2002). Design research: What we learn when we engage in design. The Journal of the Learning Sciences, 11(1), 105-121.

Freudenthal, H. (1991). Revisiting mathematics education: China lectures. Dordrecht, Netherlands: Kluwer Academic Publisher.

Gravemeijer, K., \& Cobb, P. (2006). Design research from a learning design perspective. In J. V. D. Akker, K. Gravemeijer, S. McKenney, \& N. Nieveen (Eds.), Educational design research (pp.17-51). London and New York: Routledge.

Gravemeijer, K., \& Doorman, M. (1999). Context problems in realistic mathematics education: A calculus course as an example. Educational Studies in Mathematics, 39, 111-129. https://doi.org/10.1023/A:1003749919816

Haciomeroglu, E.S., \& Andreasen, J.B. (2013). Exploring calculus with dynamic mathematics software. Mathematics and Computer Education, 47(1), 6-18.

Hohenwarter, et al., (2008). Teaching and learning calculus with free dynamic mathematics software GeoGebra. TSG 16: Research and development in the teaching and learning of calculus. ICME 11, (pp. 1-9), Monterrey, Mexico.

Lee P. Y. (2006). Teaching secondary school mathematics. Singapore: Mc Graw Hill.

Özmantar, M.F., et al., (2010). Pre-service mathematics teachers' use of multiple representations in technology-rich environments. Eurasia Journal of Mathematics, Science \& Technology Education, 6(1), 19-36.

Rasmussen, C., Marrongelle, K., \& Borba, M. C. (2014). Research on calculus: what do we know and where do we need to go? ZDM Mathematics Education 46, 507-515.

Skemp, P.R. (1976). Relational understanding and instrumental understanding. Mathematics Teaching 77, 20-26.

Treffers, A. (1987). Three dimensions (a model of goal and theory description in mathematics instruction - the wiskobas project). Dordrecht: Reidel Publishing Company.

Varberg, D., Purcell, E.J., \& Rigdon, S.E. (2007). Calculus $9^{\text {th }}$ edition. Pearson International Education: Pearson Prentice Hall

Weigand, H. G. (2014). A discrete approach to the concept of derivative. ZDM Mathematics Education, 46, 603-619. 